九州大学学術情報リポジトリ

Kyushu University Institutional Repository

\title{
Correlation of diffusion coefficients for naphthalene and dimethylnaphthalene isomers in supercritical carbon dioxide
}

Higashi, Hidenori

Department of Chemical Engineering, Faculty of Engineering, Kyushu University

Iwai, Yoshio

Department of Chemical Engineering, Faculty of Engineering, Kyushu University

Nakamura, Yuj i

Department of Chemical Engineering, Faculty of Engineering, Kyushu University

Yamamoto, Shinobu

Department of Chemical Engineering, Faculty of Engineering, Kyushu University

他

http://hdl. handle. net/2324/12534

出版情報: Fluid Phase Equilibria. 166 (1)，pp.101-110，1999-12-02. Elsevier バージョン:

権利関係: (C) 1999 Elsevier Science B.V. All rights reserved. 
Revised manuscript to Fluid Phase Equilibria (FPE 6076)

\title{
Correlation of diffusion coefficients for naphthalene and dimethylnaphthalene isomers in supercritical carbon dioxide
}

\author{
Hidenori HIGASHI, Yoshio IWAI*, Yuji NAKAMURA, \\ Shinobu YAMAMOTO and Yasuhiko ARAI \\ Department of Chemical Systems and Engineering \\ Graduate School of Engineering, Kyushu University \\ 6-10-1 Hakozaki, Higashi-ku Fukuoka 812-8581, Japan
}

Keywords : correlation, diffusion coefficient, naphthalene, dimethylnaphthalene,
carbon dioxide
* Corresponding author

Abs., Text p.1-13, Table 1-2, Fig.1-4. 


\section{ABSTRACT}

An equation proposed by Darken, including the thermodynamic factor and tracer diffusion coefficients of solvent and solute, was adopted to correlate the diffusion coefficients for naphthalene and dimethylnaphthalene isomers in supercritical carbon dioxide and the correlated results were compared with the experimental data. IML equation of state with mixing rules and combining rules containing two adjustable interaction parameters were used for calculation of the thermodynamic factor. By using the interaction parameters adjusted to the solubility data, the concentration dependence of diffusion coefficients and their anomaly near the critical point of carbon dioxide can be quantitatively represented. In order to improve the reliability of experimental results, some re-measured diffusion coefficient data for naphthalene, 2,6- and 2,7dimethylnaphthalene at $308.2 \mathrm{~K}$, and new data for naphthalene at $318.2 \mathrm{~K}$ and for 2,3dimethylnaphthalene at $308.2 \mathrm{~K}$ are presented. 


\section{INTRODUCTION}

Supercritical fluid extraction has been given much attention recently as one of the new separation technologies in the chemical industry. One of important physical properties needed for the design of supercritical extractors, separators and reactors is the diffusion coefficient of highboiling compounds in supercritical fluids. However, a measurement of diffusion coefficients under high pressures is not easy. Therefore, the diffusion coefficient data in supercritical region have been limited and thermodynamic analysis of diffusion behavior has not been fully advanced.

Recently, Liong et al. [1] have reviewed the diffusion in supercritical fluids. Nishiumi et al. [2] measured the diffusion coefficients of acetone in supercritical carbon dioxide by the Taylor-Aris method. They showed the diffusion coefficients sharply decrease near the critical point of carbon dioxide. The anomalies of diffusion coefficients of naphthalene in supercritical carbon dioxide near the critical point were also reported by Tsekhanskaya [3]. The concentration dependence and anomaly of diffusion coefficients near the critical composition for mixtures of methane and decane were reported by Dysthe and Hafskjold [4]. Bartle et al. [5], and Clifford and Coleby [6] correlated qualitatively the anomaly of diffusion coefficients for naphthalene in supercritical carbon dioxide by using van der Waals equation of state. Liong et al. [1] observed that the diffusion coefficient is essentially zero in the vicinity of the binary critical point.

In a previous work [7], the diffusion coefficients for naphthalene and dimethylnaphthalene (DMN) isomers in supercritical carbon dioxide were measured at $308.2 \mathrm{~K}$. However, the 
experimental accuracy of some data reported was found to be insufficient. In this work, therefore, the diffusion coefficients of supercritical carbon dioxide(1)-naphthalene(2) and dimethylnaphthalene isomer(2) systems were measured again carefully by using a pseudo steady state solid dissolution technique proposed by Knaff and Schlünder [8]. Improved diffusion coefficient data for naphthalene, 2,6- and 2,7-DMN at $308.2 \mathrm{~K}$, and new data for naphthalene at 318.2 $\mathrm{K}$ and for 2,3-DMN at 308.2 $\mathrm{K}$ are presented. The experimental diffusion coefficients were correlated by using the Schmidt number correlation proposed by Funazukuri et al. (see Saito [9]). Further, and the equation proposed by Darken [10] was adopted to explain their concentration dependence. In Darken equation, the thermodynamic factor and tracer diffusion coefficients of solvent and solute are needed. Therefore, IML equation of state [11] with conventional mixing rules and combining rules were used to calculate the thermodynamic factor.

\section{EXPERIMENTAL}

\section{Materials}

Reagent-grade naphthalene (more than 99.0mol\% supplied by Nacalai Tesque, Inc.), reagentgrade 2,6-DMN (more than 99.0mol\% supplied by Wako Pure Chem. Ind., Ltd.), 2,7- DMN (more than 98.0mol\% supplied by Wako Pure Chem. Ind., Ltd.), 2,3- DMN (more than 98.0mol\% supplied by Tokyo Chem. Ind. Co., Ltd.) were used. High-purity carbon dioxide, with minimum purity of 99.9\%, was supplied by Sumitomo Seiko Co,. Ltd. 


\section{Equipment and Procedures}

A flow-type apparatus was used for measurement of solubilities and a pseudo steady state solid dissolution method was adopted to measure the diffusion coefficients in supercritical carbon dioxide.

A detailed description of the equipment and procedures for measurement of solubilities and diffusion coefficients are given in previous papers [7, 12], respectively.

In this work, twelve capillaries partially filled with solid solute were attached to a diffusion cell. By flowing supercritical carbon dioxide, solid solute dissolves and diffuses in supercritical carbon dioxide. The diffusion coefficients can be obtained from both mass transfer and mass balance considerations. The expression for mass-fixed diffusion coefficient is given by Eq.(1) [8].

$$
D_{2}=\frac{\rho_{2}\left(h_{\mathrm{e}}{ }^{2}-h_{\mathrm{b}}{ }^{2}\right)}{2 m_{2} C y_{2}{ }^{\text {sat }} \Delta t}
$$

where $\rho_{2}$ and $m_{2}$ are the packed mass density and the molar mass of solid solute, respectively. $h_{\mathrm{b}}$ and $h_{\mathrm{e}}$ are the distances from the entrance of capillary to the surface of solid solute at the beginning and the end of the experiment and $\Delta t$ is the elapsed time. $h_{\mathrm{b}}, h_{\mathrm{e}}$ and $\rho_{2}$ were determined by using a micrometer with the scale to $10^{-3} \mathrm{~mm}$ and an electric balance with the scale to $10^{-5} \mathrm{mg}$. In the previous paper [7], because the scale of an electric balance was to $10^{-4} \mathrm{mg}$ and the number of capillaries used was not enough, accuracy of some data was found to be insufficient. Further, molar density $C$ and saturated solubility $y_{2}{ }^{\text {sat }}$ for carbon dioxide(1)-naphthalene(2) system were given by the data of Tsekhanskaya et al. [13]. Although the density data for carbon dioxide(1)- 
dimethylnaphthalene isomer(2) systems are not available, the densities for pure carbon dioxide are considered to be almost the same as those for these mixtures, because the saturated solubilities are sufficiently low. Therefore, the molar densities for carbon dioxide(1)-dimethylnaphthalene isomer(2) systems were replaced by the molar densities of pure carbon dioxide calculated by the equation of Angus et al. [14]. The saturated solubilities for 2,6- and 2,7-DMN were cited from the data of Iwai et al. [12] and Kurnik et al. [15]. The saturated solubilities for 2,3-DMN were measured in this study, because the diffusion coefficients obtained by using the solubilities data for 2,3-DMN of Kurnik et al. [15] are somewhat insufficient.

\section{Results and Discussion}

In order to make sure that the experimental diffusion coefficients are independent of the elapsed time and flow rate, the experiments were carried out under several elapsed times and flow rates [7]. The diffusion coefficients were determined as average values and the maximum deviation from average value was within $10 \%$. The reproducibilities were within $4 \%$ in the high pressure range above $10 \mathrm{MPa}$ and about $8 \%$ in the low pressure range below $10 \mathrm{MPa}$.

The experimental results of the diffusion coefficients for naphthalene and dimethylnaphthalene isomers in supercritical carbon dioxide are listed in Tables 1 and 2, and illustrated in Figs.1-3. The diffusion coefficients of naphthalene obtained in this study are slightly smaller than the literature data of Akgerman et al. [19] in the high pressure range. The diffusion coefficients at $308.2 \mathrm{~K}$ near 
the critical pressure of carbon dioxide decrease as shown in Fig.1. The similar phenomena of diffusion coefficients decrease for acetone and naphthalene in supercritical carbon dioxide were reported by Nishiumi et al. [2] and Tsekhanskaya [3], respectively. However, the Taylor method used by Nishiumi et al. [2] could not show the experimental concentration and the data of Tsekhanskaya [3] are so small in the wide pressure range. The diffusion coefficients of dimethylnaphthalene isomers are about $10 \%$ lower than those of naphthalene as shown in Fig.3.

The concentration dependence and anomalous decrease of diffusion coefficients near the critical composition for mixtures of methane and decane were reported by Dysthe and Hafskjold [4]. Clifford and Coleby [6] correlated the anomaly of diffusion coefficients for naphthalene in supercritical carbon dioxide by using van der Waals equation of state and they showed the decrease of diffusion coefficient in the vicinity of critical point is sensitive to the concentration of solute. Clifford and Coleby [6] calculated the diffusion coefficients and discussed about the concentration dependency. However, they did not compare the calculated results with experimental data.

\section{CORRELATION}

\section{Diffusion coefficient at infinite dilution}

The Schmidt number correlation proposed by Funazukuri et al. (see Saito [9]) was used to calculate the diffusion coefficients at infinite dilution. The detail of the Schmidt number correlation was shown in a previous paper [7]. Under the infinite dilution, the mass-fixed diffusion coefficient 
equals to the mutual diffusion coefficient.

Diffusion coefficient at finite concentration

According to a non-equilibrium thermodynamics theory [20], the mass-fixed diffusion coefficient is related to the mutual diffusion coefficient, $D_{21}\left(=D_{12}\right)$, under the finite concentration.

$$
D_{2}=\frac{D_{21}}{C \overline{v_{1}}}
$$

The correlation of concentration dependence for mutual diffusion coefficient proposed by

Darken [15] is shown by

$$
D_{21}=\left(y_{2} D_{1}^{*}+y_{1} D_{2}^{*}\right) \alpha
$$

where $y$ and $D^{*}$ are the mole fraction and tracer diffusion coefficient, respectively. $\alpha$ is the thermodynamic factor and is given by the following expression.

$$
\alpha=\left(\frac{\partial \ln f_{2}}{\partial \ln y_{2}}\right)
$$

where $f_{2}$ is the fugacity of solute.

As the solubility for naphthalene in supercritical carbon dioxide is about $10^{-3}$ order and the concentration dependence of tracer diffusion coefficient is very small, the concentration dependent diffusion coefficients can be represented by

$$
D_{2}=\frac{\left(y_{2} D_{11}+y_{1} D_{21}{ }^{0}\right)}{C \bar{v}_{1}}\left(\frac{\partial \ln f_{2}}{\partial \ln y_{2}}\right)
$$

where $D_{11}$ and $D_{21}{ }^{0}$ are the self diffusion coefficient of component 1 and infinite dilution diffusion 
coefficient of component 2, respectively.

In the correlation, the fugacity was calculated by IML equation of state [11] and the mole fraction of solute, $y_{2}$, was assumed to be the half of the saturated solubility. Because the average mole fraction in the diffusion cell may be approximated by $y_{2}{ }^{\text {sat }} / 2$, where $y_{2}{ }^{\text {sat }}$ is the saturated mole fraction of solute at the solid sample surface. IML equation of state is shown as follows.

$$
P=\frac{R T}{v-b}-\frac{a}{v^{2}-c(v-b)}
$$

where $a, b, c$ are the energy and size parameters calculated by the critical properties. The mixing and combining rules for mixture are shown in Eqs.(7)-(9).

$$
\begin{array}{ll}
a_{\mathrm{m}}=\sum_{i} \sum_{j} y_{i} y_{j} a_{i j}, & a_{i j}=\left(1-k_{i j}\right) \sqrt{a_{i} a_{j}} \\
b_{\mathrm{m}}=\sum_{i} \sum_{j} y_{i} y_{j} b_{i j}, & b_{i j}=\left(1-l_{i j}\right)\left(b_{i}+b_{j}\right) / 2 \\
c_{\mathrm{m}}=\sum_{i} \sum_{j} y_{i} y_{j} c_{i j}, & c_{i j}=\left(1-l_{i j}\right)\left(c_{i}+c_{j}\right) / 2
\end{array}
$$

where $k_{i j}$ and $l_{i j}$ are the interaction parameters between unlike molecules, which were adjusted by the solubility data.

\section{Results and Discussion}

Correlation results for the solubilities and the optimum values of $k_{12}$ and $l_{12}$ are shown in Fig.4. The calculation results for the diffusion coefficients in supercritical carbon dioxide at infinite dilution and finite concentration are illustrated in Figs.1-3. The calculation results of diffusion coefficients for naphthalene at infinite dilution show good agreement with the data of Akgerman et 
al. [16], which were measured at the accurate infinite dilution condition. The correlation results of diffusion coefficients for naphthalene at finite concentration qualitatively represent the anomalous decrease at $308.2 \mathrm{~K}$ and those for naphthalene and dimethylnaphthalene isomers under high pressures are in good agreement with the experimental data.

\section{CONCLUSION}

The Schmidt number correlation for infinite dilution condition and Darken equation for concentration dependence of diffusion coefficients were adopted to correlate the diffusion coefficients for naphthalene and dimethylnaphthalene isomers in supercritical carbon dioxide. The Schmidt number correlation shows good agreement with the literature data measured at infinite dilution conditions. Darken equation can quantitatively represent the concentration dependence and the anomalous decrease of diffusion coefficients near the critical pressure, by using interaction parameters adjusted to the solubility data. The anomalous decrease of diffusion coefficient near the critical pressure of carbon dioxide are observed for naphthalene + supercritical carbon dioxide system at $308.2 \mathrm{~K}$ from the experimental data and the correlation results using by the Darken equation.

\section{ACKNOWLEDGMENTS}

We gratefully acknowledge the financial support provided by "Research for the Future" 
Program (96P00401), The Japan Society for the Promotion of Science, and Grant-in-Aid for Encouragement of Young Scientist (10750551), The Ministry of Education, Science and Culture.

\section{NOMENCLATURE}

a energy parameter $\left[\mathrm{Pa} \mathrm{m}^{6} \mathrm{~mol}^{-2}\right]$

$b, c \quad$ size parameters $\left[\mathrm{m}^{3} \mathrm{~mol}^{-1}\right]$

C molar density $\left[\mathrm{mol} \mathrm{m}^{-3}\right]$

D diffusion coefficient $\left[\mathrm{m}^{2} \mathrm{~s}^{-1}\right]$

f fugacity

$h \quad$ distance from surface of packed solid solute to capillary entrance

$k, l \quad$ interaction parameters

m molar mass

$P \quad$ pressure

$R \quad$ gas constatt

Sc Schmidt number

$T$ absolute temperature

$t \quad$ time

$v \quad$ molar volume

$\bar{v} \quad$ partial molar volume 
Greek letters

$\alpha \quad$ thermodynamic factor

$\rho \quad$ mass density

$\left[\mathrm{kg} \mathrm{m}^{-3}\right]$

\section{Subscripts}

b beginning of experiment

e end of experiment

$i, j \quad$ components $i$ and $j$

1 solvent (supercritical carbon dioxide)

2 solute (naphthalene and dimethylnaphthalene)

\section{Superscripts}

sat saturated

$0 \quad$ infinite dilution

* tracer diffusion 


\section{REFERENCES}

[1] K.K. Liong, P.A. Wells and N.R. Foster, J. Supercritical Fluids, 4 (1991) 91-108.

[2] H. Nishiumi, M. Fujita and K. Agou, Fluid Phase Equilibria, 117 (1996) 356-363.

[3] Y.V. Tsekhanskaya, Russ. J. Phys. Chem., 45 (1971) 744.

[4] D.K. Dysthe and B. Hafskjold, Int. J. Thermophys., 16 (1995) 1213-1224.

[5] K.D. Bartle, D.L. Baulch, A.A. Clifford and S.E. Coleby, J. Chromatograpy, 557 (1991) 69-83.

[6] A.A. Clifford and S.E. Coleby, Proc. R. Soc. Lond. A, 433 (1991) 63-79.

[7] H. Higashi, Y. Iwai, Y. Takahashi, H. Uchida and Y. Arai, Fluid Phase Equilibria, 144 (1998) 269-278.

[8] G. Knaff and E.U. Schlünder, Chem. Eng. Process, 21 (1987) 101-105.

[9] S. Saito, J. Supercritical Fluids, 8 (1995) 177-204.

[10] L.S. Darken., Trans. Am. Inst. Mining Metall Eng., 175 (1948) 184.

[11] Y. Iwai, M.R. Margerum and B.B.-Y. Lu, Fluid Phase Equilibria, 42 (1988) 21-41.

[12] Y. Iwai, Y. Mori, N. Hosotani, H. Higashi, T. Furuya, Y. Arai, K. Yamamoto and Y. Mito, J. Chem. Eng. Data, 38 (1993) 509-511.

[13] Y.V. Tsekhanskaya, M.B. Iomtev and E.V. Mushkina, Russ. J. Phys. Chem., 38 (1964) 11731176.

[14] S. Angus, B. Armstrong and K.M. de Reuck, Carbon Dioxide: International Thermodynamic Tables of the Fluid State-3, Pergamon Press, New York, 1976. 
[15] R.T. Kurnik, S.J. Holla and R.C. Reid, J. Chem. Eng. Data, 26 (1981) 47-51.

[16] M.B. Iomtev and Y.V. Tsekhanskaya, Russ. J. Phys. Chem., 38 (1964) 485-487.

[17] D.M. Lamb, S.T. Adamy, K.W. Woo and J. Jonas, J. Phys. Chem., 93 (1989) 5002-5005.

[18] K.K. Liong, P.A. Wells and N.R. Foster, Ind. Eng.Chem.Res., 30 (1991) 1329-1335.

[19] A. Akgerman, C. Erkey and M. Orejuela, Ind. Eng. Chem. Res., 35 (1996) 911-917.

[20] D.D. Fitts, Nonequilibrium Thermodynamics, McGraw-Hill, New York, 1962. 
Table 1. Diffusi on coeffi ci ent s of napht hal ene( 2) in supercritical carbon di oxi de( 1)

\begin{tabular}{|c|c|c|c|c|}
\hline Temperature [K] & $P[\mathrm{MPa}]$ & $C\left[\mathrm{~mol} \mathrm{~cm}{ }^{-3}\right] *$ & $y_{2}^{\text {sat }}[-] *$ & $D_{2} \times 10^{8}\left[\mathrm{~m}^{2} \mathrm{~s}^{-1}\right]$ \\
\hline \multirow[t]{22}{*}{308.2} & 7.70 & 0.00690 & 0.00087 & 2.99 \\
\hline & 7.92 & 0.00901 & 0.00182 & 2.75 \\
\hline & 7.94 & 0.0100 & 0.00251 & 2.50 \\
\hline & 7.97 & 0.0111 & 0.00342 & 2.29 \\
\hline & 7.99 & 0.0113 & 0.00358 & 1.96 \\
\hline & 8.02 & 0.0119 & 0.00412 & 1.75 \\
\hline & 8.03 & 0.0121 & 0.00432 & 1.56 \\
\hline & 8.07 & 0.0129 & 0.00529 & 1.45 \\
\hline & 8.10 & 0.0133 & 0.00611 & 1.37 \\
\hline & 8.12 & 0.0135 & 0.00628 & 1.27 \\
\hline & 8.13 & 0.0136 & 0.00636 & 1.12 \\
\hline & 8.14 & 0.0137 & 0.00644 & 1.22 \\
\hline & 8.15 & 0.0138 & 0.00651 & 1.25 \\
\hline & 8.18 & 0.0140 & 0.00671 & 1.30 \\
\hline & 8.23 & 0.0143 & 0.00697 & 1.28 \\
\hline & 8.54 & 0.0152 & 0.00784 & 1.25 \\
\hline & 8.80 & 0.0156 & 0.00834 & 1.23 \\
\hline & 10.4 & 0.0169 & 0.0108 & 1.11 \\
\hline & 11.8 & 0.0175 & 0.0122 & 1.09 \\
\hline & 13.3 & 0.0181 & 0.0133 & 1.01 \\
\hline & 15.2 & 0.0186 & 0.0146 & 0.93 \\
\hline & 20.0 & 0.0199 & 0.0166 & 0.85 \\
\hline \multirow[t]{13}{*}{318.2} & 8.75 & 0.00690 & 0.00125 & 2.80 \\
\hline & 9.23 & 0.00840 & 0.00214 & 2.61 \\
\hline & 9.35 & 0.00909 & 0.00272 & 2.28 \\
\hline & 9.60 & 0.0108 & 0.00442 & 1.86 \\
\hline & 9.79 & 0.0116 & 0.00522 & 1.77 \\
\hline & 9.92 & 0.0122 & 0.00604 & 1.61 \\
\hline & 10.3 & 0.0134 & 0.00807 & 1.50 \\
\hline & 10.6 & 0.0142 & 0.00970 & 1.38 \\
\hline & 11.1 & 0.0149 & 0.0120 & 1.26 \\
\hline & 11.8 & 0.0157 & 0.0140 & 1.25 \\
\hline & 13.7 & 0.0168 & 0.0174 & 1.12 \\
\hline & 15.3 & 0.0175 & 0.0195 & 1.10 \\
\hline & 19.9 & 0.0186 & 0.0242 & 0.95 \\
\hline
\end{tabular}

* Tsekhanskaya et al. [13] 
Table 2. Diffusion coefficients of dimethylnaphthalene isomer(2) in supercritical carbon dioxide(1) at $308.2 \mathrm{~K}$

\begin{tabular}{ccccc}
\hline Component & $P[\mathrm{MPa}]$ & $C\left[\mathrm{~mol} \mathrm{~cm}^{-3}\right]^{\mathrm{a}}$ & $y_{2}{ }^{\mathrm{sat}}[-]$ & $D_{2} \times 10^{8}\left[\mathrm{~m}^{2} \mathrm{~s}^{-1}\right]$ \\
\hline 2,6-dimethyl- & 9.10 & 0.0152 & $0.00195^{\mathrm{b}}$ & 1.07 \\
naphthalene & 14.6 & 0.0184 & $0.00306^{\mathrm{b}}$ & 0.91 \\
& 19.5 & 0.0196 & $0.00383^{\mathrm{c}}$ & 0.78 \\
\hline 2,7-dimethyl- & 10.7 & 0.0167 & $0.00351^{\mathrm{b}}$ & 1.02 \\
naphthalene & 15.0 & 0.0185 & $0.00472^{\mathrm{b}}$ & 0.86 \\
& 20.0 & 0.0197 & $0.00529^{\mathrm{b}}$ & 0.79 \\
\hline 2,3-dimethyl- & 9.90 & 0.0152 & $0.00273^{\mathrm{d}}$ & 1.10 \\
naphthalene & 14.3 & 0.0183 & $0.00409^{\mathrm{d}}$ & 0.88 \\
& 19.4 & 0.0196 & $0.00469^{\mathrm{d}}$ & 0.81 \\
\hline
\end{tabular}

\footnotetext{
${ }^{\text {a }}$ Angus et al. [14]

${ }^{\mathrm{b}}$ Iwai et al. [12]

${ }^{\mathrm{c}}$ Kurnik et al. [15]

d This work.
} 
Fig.1 Diffusion coefficients of naphthalene at 308.2 K. Experimental: ( $\mathbf{O}$ ) Tsekhanskaya [3]; $(\diamond)$ Knaff and Schlunder. [8]; (O) Iomtev and Tsekhanskaya [16]; ( $\triangle$ ) Lamb et al. [17];

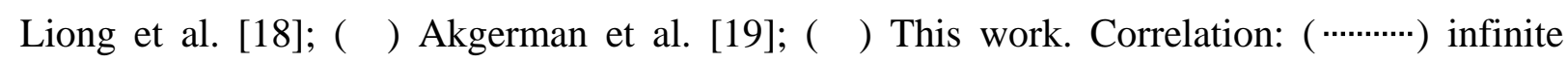
dilution; $(\longrightarrow)$ finite concentration.

Fig.2 Diffusion coefficients of naphthalene at 318.2 K. Experimental: $(\diamond)$ Knaff and Schlunder. [8]; (O) Iomtev and Tsekhanskaya [16]; ( $\square$ ) Liong et al. [18]; ( $\nabla$ ) Akgerman et al. [19]; (○) This work. Correlation: ( ...........) infinite dilution; ( - ) finite concentration.

Fig.3 Diffusion coefficients of dimethylnaphthalene isomers at $308.2 \mathrm{~K}$. Experimental: $(\triangle)$ 2,6dimethylnaphthalene; ( $\square$ ) 2,7-dimethylnaphthalene; ( $\diamond$ ) 2,3-dimethylnaphthalene. Correlation: ( …….... ) dimethylnaphthalene isomers, infinite dilution; ( - - - ) 2,6dimethylnaphthalene; (- - - ) 2,7-dimethylnaphthalene; ( - - - ) 2,3-dimethylnaphthalene, finite concentration. 
Fig.4 Solubilities of naphthalene and dimethylnaphthalene isomers. Experimental: $(\bigcirc) 308.2$ K;

(O) 318.2 K, Tsekhanskaya et al. [13], naphthalene; ( $\triangle$ ) Iwai et al. [12]; ( $\mathbf{\Delta})$ Kurnik et al. [15], 2,6-dimethylnaphthalene; $(\square)$ Iwai et al. [12], 2,7-dimethylnaphthalene; $(\diamond)$ This work, 2,3dimethylnaphthalene. Correlation: ( $\quad$ 308.2 K; $\quad$ ) 318.z K, naphthalene $\left(k_{12}=0.020\right.$, $\left.l_{12}=-0.129\right) ; \quad(\quad) \cdot 2 ; 6$-dimethylnaphthalene $\left(k_{12}=0.027, l_{12}=-0.039\right) ; \quad(\quad-\rightarrow 2,7-$ dimethylnaphthalene $\left(k_{12}=0.010, l_{12}=-0.073\right) ;(-\cdots-)$ 2,3-dimethylnaphthalene $\left(k_{12}=-0.008\right.$, $\left.l_{12}=-0.097\right)$. 


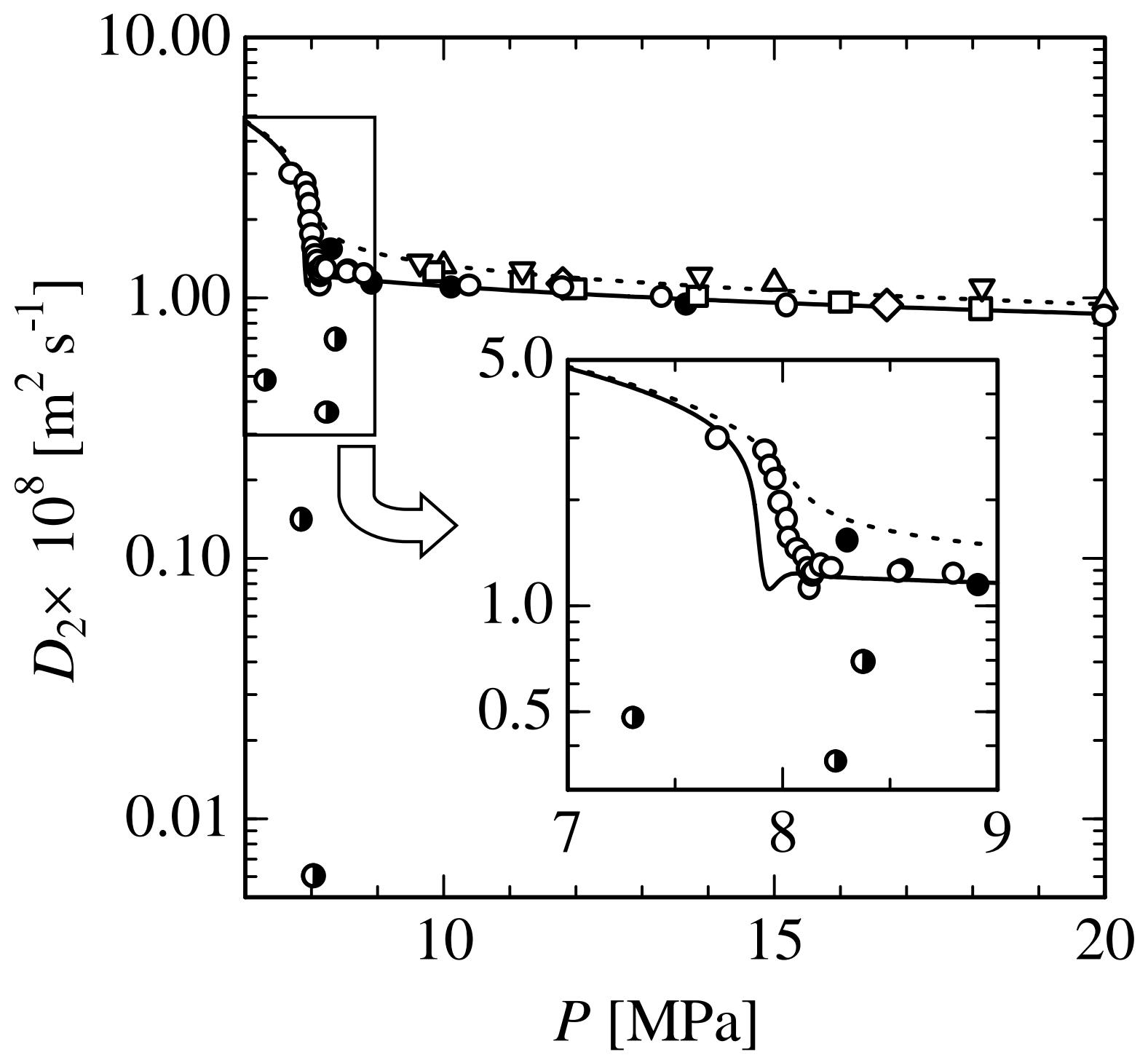




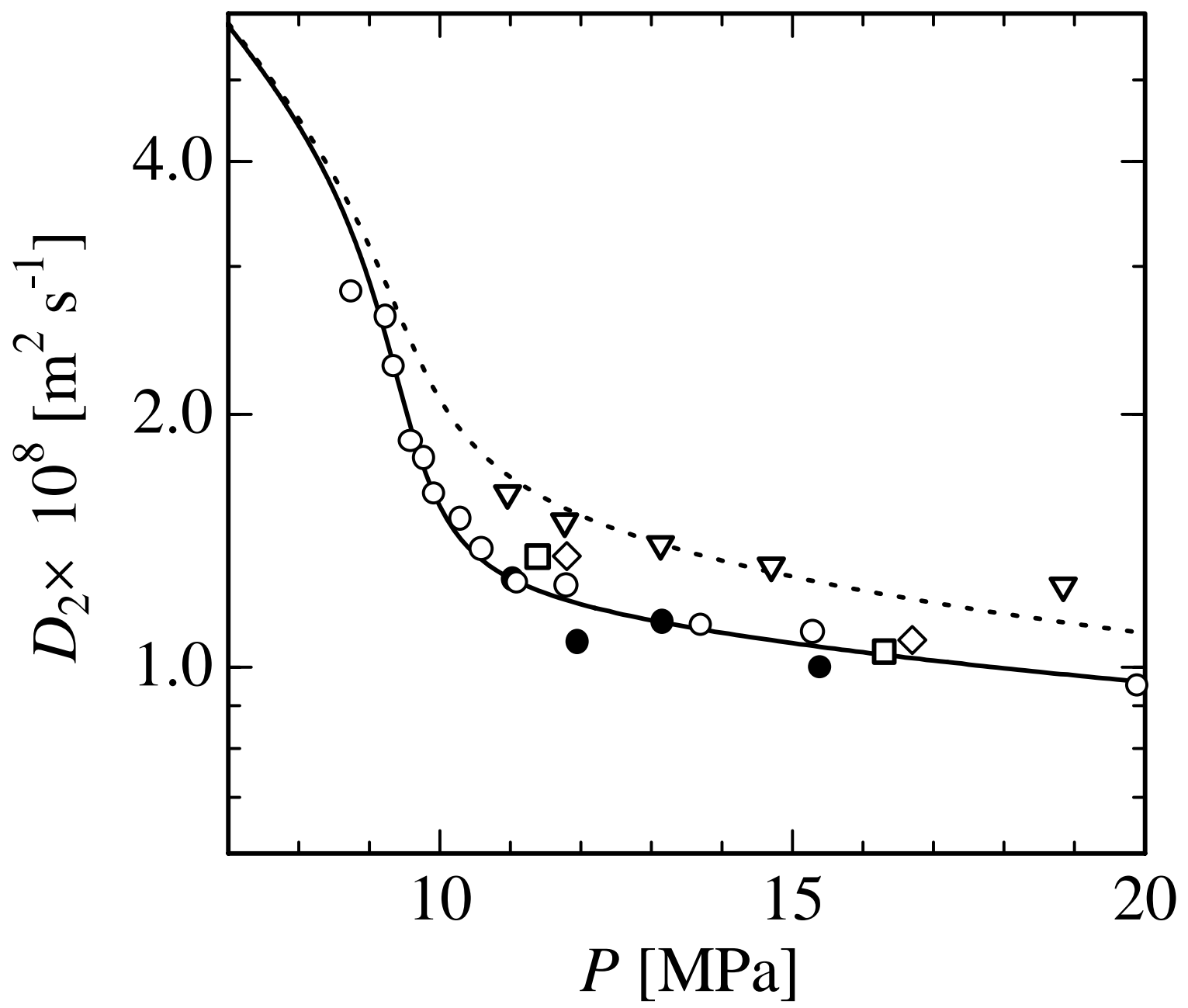




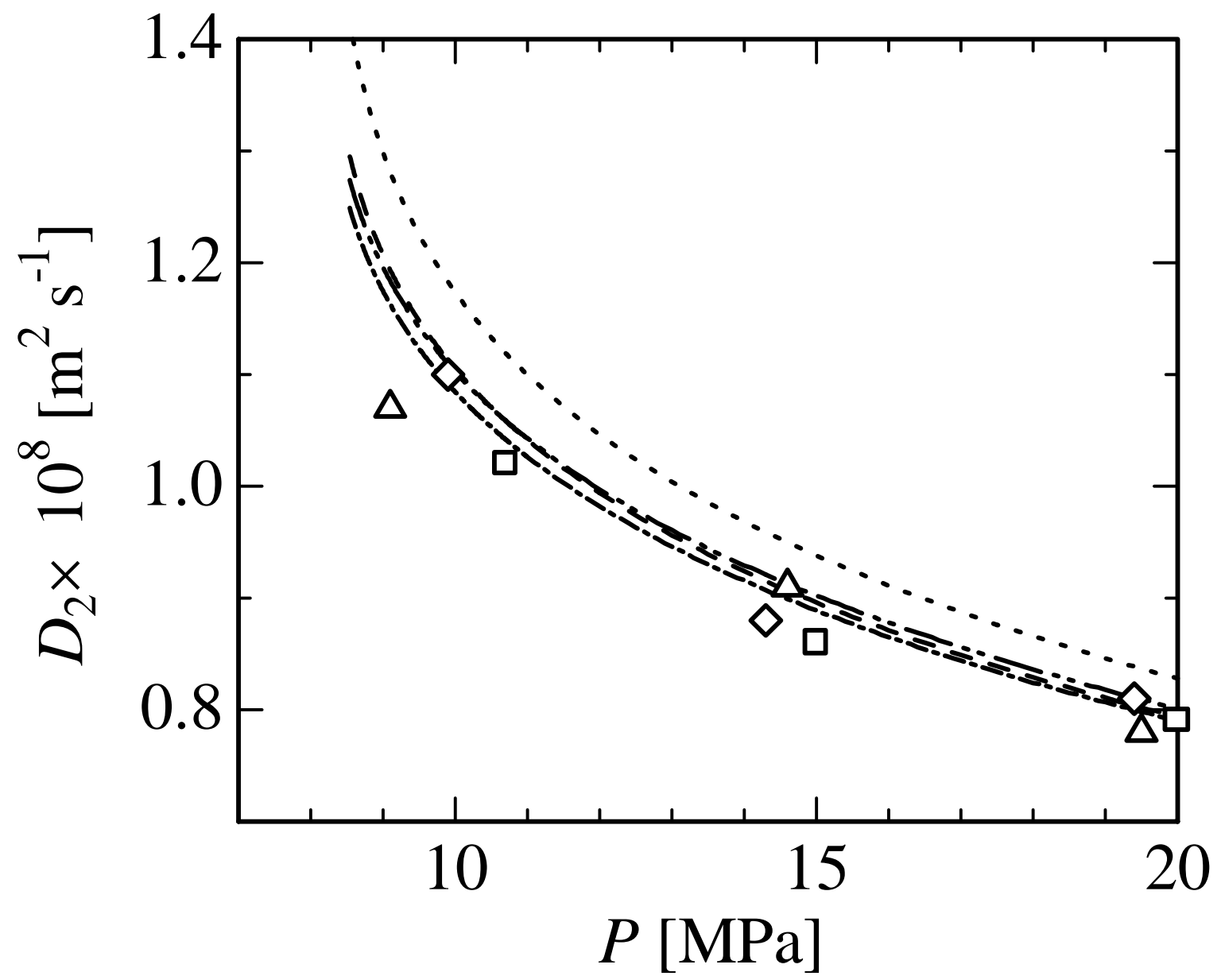




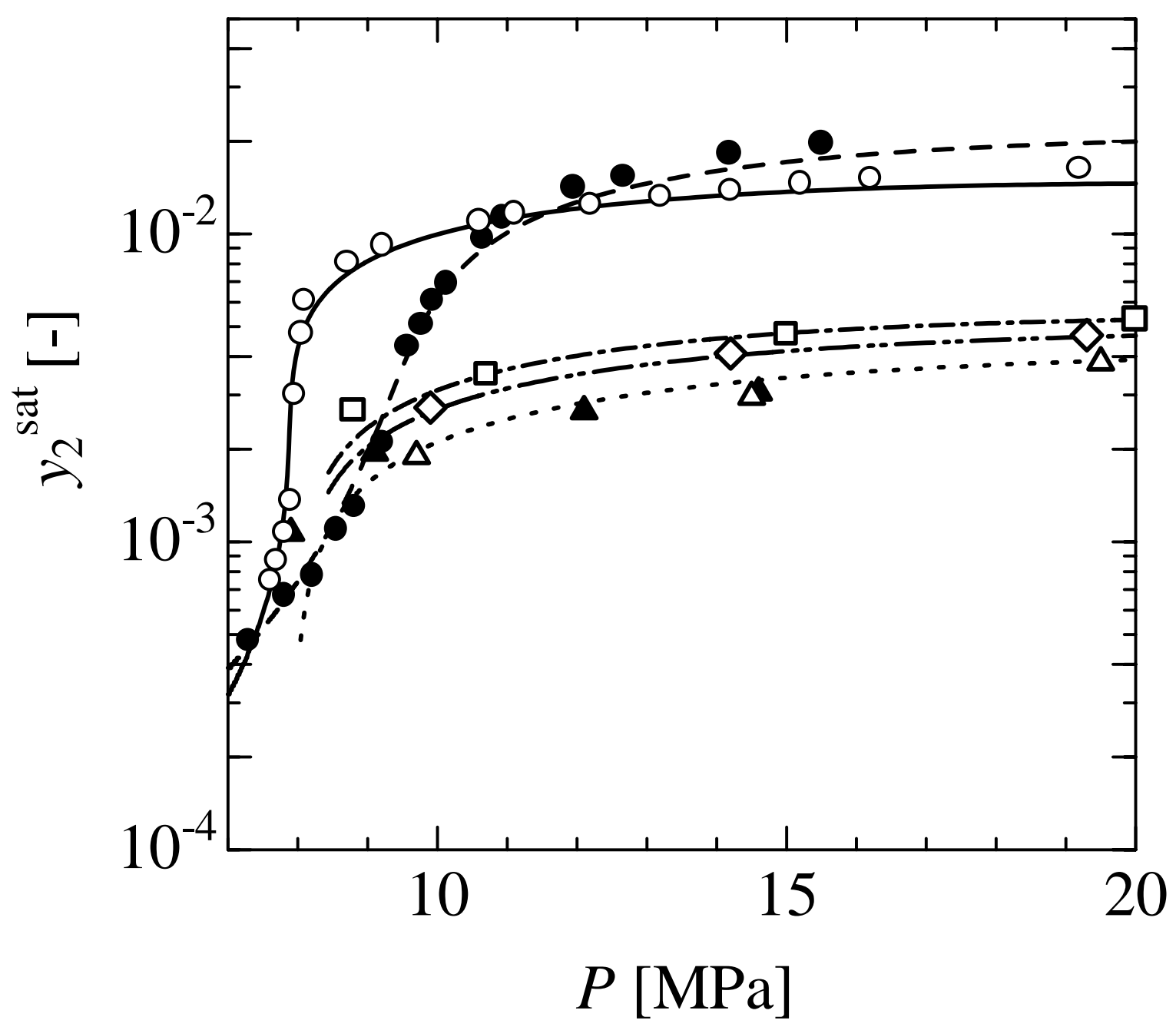

